to obtain a fix is essential if 'astro' is to survive as a premier aid to navigation. He welcomed the practical suggestions made, particularly the possibility of zenith photography, but reiterated the need for vertical stabilization.

The present state of the investigations into this problem was summarized by Mr. W. A. W. Fox, who briefly listed seven possible datums: free horizon, normal reflexion from water surface, haze levels, pressure isobaric levels, the magnetic field of the earth, cosmic rays, and the gravitational field of the earth. The first six are either of very limited application or involve great difficulties, thus leaving only the last. The Melville-Jones theorem (that the average altitude equals the true altitude if the track and ground speed at beginning and end of the run are the same) offers possibilities, but fatigue factor limits the use of the sextants. The perfect solution is the Schuler pendulum, of period 84 minutes-the same as that of the free earth; present attempts to make a gyro with a low wander-rate fall short by a factor of 100-1,000.

Dr. G. N. Harvey appealed for greater use of the magnetic field of the earth, both as a datum and as a position fixing system. Mr. T. H. O'Bierne suggested that the present bulk of tables for astronomical navigation can be substantially reduced by using optical methods of enlargement from very small figures or from microfilms. Wing Commander $\mathrm{E}$. Anderson compared 'astro' with radio methods, particularly the radio compass, and suggested that, if practicable, the whole basis of the information provided by 'astro' should be changed from position fixing to telling the navigator what to do. If the almanacs could tabulate altitude and azimuth for certain specific points (destinations), the navigator could utilize the principle of astro-ranges (analogous to radio-ranges or the use of the radio compass) to enable him to home. Such a method would have the advantage that its accuracy would increase as the destination was approached, and that individual observations could be continuously integrated. Squadron Leader D. Bower summarized practical experience in relation to the time taken by navigators to obtain a two- or three-star fix; he quoted figures of $25 \mathrm{~min}$. and $22 \mathrm{~min}$. for the relative times of obtaining a two-star fix with the Astronomical Navigation Tables and H.O. 249-reduced to 19 and 13 min. respectively when two navigators are carried,

\section{CONDUCTION IN GERMANIUM: THE TRANSISTOR}

CINCE the initia 1 publications by Bardeen and $\checkmark$ Brattain (s) Nature, Dec. 25, 1948, p. 982) on the transifor, several articles have appeared and talks hove been given by members of the Bell Teleph ne Laboratories staff describing in further detail the characteristics of the device and the theory of its action. Considerable progress has been made both in examination of the properties of the materials used and in the development of transistors for production. Various problems still remain to be solved, however, notably reduction in noise, and increase in the frequency limit, in addition to an improvement in the production of units with reproducible characteristics.

A comprehensive survey of the physical principles involved in transistor action, in which is included an outline of the history of the development, new data on the characteristics of the device, a discussion of the nature of electrical conduction in germanium and of the theory of the germanium point-contact rectifier, and an extensive detailed bibliography, has recently been given in the Physical Review (75, 1208-25; April 15, 1949) by the discoverers. The discussion is confined to the transistor, in which two contacts, the emitter and collector, are placed close to each other on one face of a germanium block; but the same principles are applicable to other geometrical arrangements, and to other semiconductors, for example silicon, on which some preliminary,work has already been done.

In the transistor there is a voltage gain and a power gain of an input signal, and possibly also a current amplification. The current multiplication factor (the rate of change of collector current with respect to emitter current at constant collector voltage) is, in typical units, of the order of 1-3. The dependence of this factor on bias voltage, frequency, temperature, and electrode spacing is discussed. Early experiments suggested that positive holes flow from the emitter to the collector along the surface of the germanium; but it has since been established that holes may flow either through the surface layer or through the body of the semiconductor. Estimates which are made of the orders of magnitude of the field produced by the collector current, the transit time for holes, the space charge produced by holes flowing into the collector, and the feedback resistance, confirm the general picture given of transistor action.

\section{APPOINTMENTS VACANT}

APPLICATIONS are inyited for the following appointments on or before the dates mentio led

GRADDATE LECTURH MATHEMATICS for Degree and Higher IN BrougieA SubJy cTS-The Principal, Central Technical College,

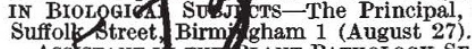

Suffolk street, Birm, gham 1 (August 27).
Ass diseas 1 of fruit and hops--The Secretary, East Malling Research diseas 0 fruit and hops-The Secretary, East

Assistant ChEMIST (Grade VI), an Assistant CHeMist (Grade V), an Assistant CHEMIST (Grade III), and an ASSISTANT CHEMIST (Grade I)-The Chief Engineer, Middlesex County Council Main Drainage Department, Isleworth, Middx., quoting F.909.T (August 29). ASSISTANT LECTURER IN HISTOLOGY AND EMBRYOLOGY-ThE Secretary, Royal Veterinary College and Hospital, Royal College Street, London, N.W.1 (August 31).

Assistant STATSTician in the Central Statistical office of the Town Clerk's Department-The Town Clerk, Room 30B, Counci House, Birmingham 1, endorsed 'Assistant Statistician' (September 2) SENIOR EXPERIMENTAL OFFICERS and EXPERMMENTAL OFFICERS for work connected with design and development of large wind tunnels and associated aerodynamic research equipment at the Royal Aircraft Establishment, Farnborough-The Technical and Scientifle Register (K), York House, Kingsway, London, W.C.2, quoting C.475/49A (September 3).

ASSISTANT LECTURER IN PHYSICS-The Secretary, St. Mary's Hospital Medical School, Paddington, W.2 (September 3).

Lecturer in Natural Phrlosophy in University College, Dundee - The Secretary, The University, St. Andrews (September 3).

CHEMIST as Deputy Municipal Analyst, Municipality of SingaporeMessrs. Peirce and Williams, 1 Victoria Street, London, S.W.1 (September 3).

ASSISTA NT IN ENTOMOLOGY with particular reference to ForestryThe Secretary, The University, Old College, South Bridge, Edinburgh (September 3).

PRINCIPAL SCIENTIFIC OFFICERS at the Royal Aircraft Establishment, Farnborough, (a) (Ref. C.470/49A) to carry out and supervise research into fatigue of aircraft structures, $(b)$ (Ref. C.471/49A) to take charge of section carrying out research into behaviour of materials and structural elements for use of aircraft designers, etc., $(c)$ (Ref C.472/49A) to carry out and supervise research into fundamenta theory of structures, primarily from the standpoint of aircraft-The Technical and Scientific Register (K), York House, Kin
W.C.2, quoting appropriate Ref. No. (September 5).

W.C.2, quoting appropriate Ref. No. (September 5).
SENYOR ScIENTIFIC OFFICER (with good degree in chemistry, physics, SENIOR ScIENTIFIC OFFICER (with good degree in chemistry, physics,
mathematics or engineering, together with research experience) in London under the Ministry of Supply, for scientific administration work, involving evaluation of scientiflc reports, advising administrativ staff, committee work, etc.-The Technical and Scientific Register (K), York House, Kingsway, London, W.C.2, quoting F.528/49A (Septem. ber 5 ). 